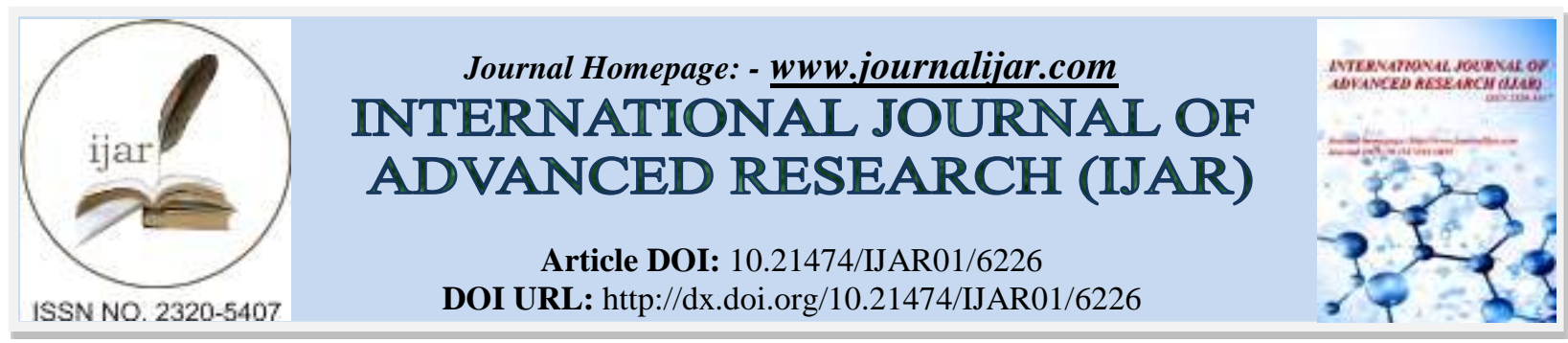

RESEARCH ARTICLE

\title{
ANTIBIOTIC USE AND AWARENESS AMONG VISITORS OF NATIONAL GUARD PRIMARY HEALTH CARE CENTERS.
}

\author{
Ahmed Mohammed Alfaidi, Mohammed Abdullah Babgi, Samer Abdulmoghny Alamri and Abdulaziz \\ Abdulnasir Aldahlawi. \\ King Saud bin Abdulaziz University for Health Sciences - Jeddah, Saudi Arabia.
}

\section{Manuscript Info}

Final Accepted: 07 December 2017

Published: January 2018
Manuscript History

Received: 05 November 2017

\section{Abstract}

Background: Misuse of antimicrobial agents has led to the emergence of the global antibiotic resistance. The three main aspects that can contribute to antibiotic resistance are physicians, pharmacists and patients. Patients in Saudi Arabia can have easy access to antibiotics, which further contributes to the development of resistance. Our aim in this study is to address the patient aspect in regards to their usage patterns and knowledge of antibiotics in primary health care centers, Ministry of National Guard, Jeddah - Saudi Arabia.

Methods: A cross sectional study was conducted from February to June 2016 at National Guard's primary health care centers in Jeddah city. Self-administered ArabiclEnglish questionnaires were distributed with convenient sampling technique.

Results: Four hundred and five questionnaires were collected from four primary health care centers. There were $56.3 \%$ females $(\mathrm{n}=228)$ and mean (SD) age was 31.7 (11.7) years. Seventy percent of the participants reported antibiotic use in the past year. More than half (55.8\%) would use antibiotics when they have common cold and $40.1 \%$ would recommend antibiotic medication based on their experience. Only $47.9 \%$ will stop antibiotic course when completed. The overall compliance was $65.2 \%$. Among antibiotic complaint patients, $76.5 \%$ $(\mathrm{n}=186)$ have physician antibiotic prescriptions in comparison to $23.5 \%$ who received non physician prescriptions (pharmacist, others recommendations, own decision), however, $52.9 \%$ never heard of the term antibiotic resistance.

Conclusion: Relatively good compliance was associated with physician antibiotic prescriptions. More than half of the population showed inappropriate antibiotic use. Both compliance and inappropriate use can impact the prevalence of antibiotic resistance in the region, necessitating further control and education over antibiotics use.

Copy Right, IJAR, 2018,. All rights reserved.

\section{Introduction:-}

Antibiotics are the mainstay in treatment and prevention of a wide variety of diseases and infections. The global antibiotic consumption increased by more than $30 \%$ over the past decade (1). However, the misuse and overuse of 
antibiotics have led to the development of antimicrobial resistance. It is estimated that antibiotic resistance causes 23000 deaths per year in the United States (2). The misuse can be attributed to different factors, such as inappropriate prescription, unregulated selling and dispensing, and the lack of patients' knowledge about antibiotics. The use of antibiotics when not indicated, such as prescribing antibiotics for viral upper respiratory tract infections (URTI), plays a major role in the development of antimicrobial resistance. In addition, the easy access for antibiotics can lead to unnecessary use. It is estimated that $80 \%$ of antibiotics are used outside hospitals, while in Saudi Arabia $78 \%$ of pharmacies are dispensing antibiotics without physicians' prescription (1). The patients' knowledge about antibiotics in regard to their appropriate uses, benefits, and side effects is a significant factor. In a multi-country survey, $64 \%$ of surveyed participants said that antibiotics can be used to treat common cold (3). Another factor that contributes to the emergence of resistance is the extensive agricultural use of antibiotics, such as in livestock production (4). All these factors and behaviors increase the global burden of antimicrobial resistance. The aim of this study is to address the patient aspect in regard to their usage patterns and knowledge of antibiotics in primary health care centers, Ministry of National Guard, Jeddah - Saudi Arabia.

\section{Methods:-}

This is a cross-sectional study conducted between February and June 2016 in National Guard primary healthcare clinics and the ambulatory care center in Jeddah city, Saudi Arabia. Questionnaires were distributed in four primary care centers; Iskan clinic, ambulatory care center (ACC), Bahra clinic, Al-Waha polyclinics. A convenient sampling technique was used in which all patients or visitors who agreed to participate following an informed oral consent were included. The questionnaire consisted of demographic information, patterns of antibiotic use, adherence, and knowledge of antibiotic resistance.

\section{Results:-}

Four hundred and five questionnaires were collected from four primary health care centers in Jeddah city. Hundred questionnaires were distributed equally in each of the studied centers. Our sample included 56.3\% females ( $\mathrm{n}=228$ ) with $27.8 \%$ of them being housewives. The mean (SD) age for the total sample was $31.7 \pm 11.7$ years and $64.9 \%$ of them were married [Table 1].

Fifteen patients did not report their educational status; the remaining 390 participants were undergraduates ( $\mathrm{n}=207$, $53.1 \%)$ and postgraduates $(n=183,46.9 \%)$. Most of the participants work in the military, followed by students then non-medical professions $(27.5 \%, 23.3 \%$ and $21.2 \%$, respectively).

Seventy percent of the participants $(n=277)$ reported antibiotic use in the past year, of whom $78 \%(n=216)$ reported the reason of antibiotics intake. The most common reason was URTI in $(n=144,66.7 \%)$, followed by dental problems in $(n=23,10.6 \%)$. About half of the participants $(52.9 \%)$ never heard of the term antibiotic resistance, and only $47.8 \%$ thought that the effectiveness of antibiotic will decrease with repetitive use. Moreover, $40.1 \%$ would recommend antibiotic medications based on their experience, and $42.4 \%$ mentioned that they do not read the drug pamphlets. More than half of the participants (55.8\%) would use antibiotics when they have common cold [Table 2]. Only $47.9 \%$ would stop antibiotics when they complete the recommended course, while $42.2 \%$ would stop antibiotics when symptoms improve. However, 6.3\% mentioned that they stop antibiotic course due to side effects and $3.6 \%$ because they see no improvement [Graph 1]. Around twenty eight percent of the participants purchased the antibiotic without physician prescription. Compliance of participants was determined by their adherence to the exact instructions of the prescribed antibiotic. Change of dose or duration was considered non-compliance. The overall compliance was $65.2 \%$ among the participants. Out of complaint participants, $76.5 \%$ (n=186) have physician antibiotic prescriptions and the remaining $(n=57,23.5 \%)$ received non-physician prescriptions, such as pharmacist, others recommendations, or own decision [Graph 2].

\section{Discussion:-}

Antibiotics are the corner stone in treating most infectious diseases. However, antibiotics overuse can lead to resistance, affecting their therapeutic value and the overall cost of the treatment. This is a main concern in Saudi Arabia according to many studies conducted throughout the country. According to Alanazi et al. (5), only 38.7\% have heard of the term antibiotic resistance, compared to the percentage found in our study (47.1\%). It was also mentioned that patients took the antibiotic without prescriptions because the physician prescribed the same antibiotic for the same symptoms previously, followed by the pharmacist recommendation for the drug as the second most common reason for taking antibiotics without prescription. In another study by Al-Mohamadi et al. (6) in private 
pharmacies in Jeddah city, there were 46 antibiotics were dispensed by the pharmacist without asking for any indications or physician prescription out of 48 requests for antibiotics. A similar study in Riyadh, the investigators had prepared predetermined clinical scenarios to be simulated in pharmacies (7). Antibiotics were dispensed from $77.6 \%$ of the total sample involved, with none of them asking about allergy or drug interactions. Furthermore, $90 \%$ of the dispensed antibiotics were not even requested by the actors. Moreover, the most common scenarios given to the pharmacists were diarrhea and sore throat, which are not necessarily due to bacterial causes. Likewise, a multicountry survey done by WHO showed that $64 \%$ of the involved population believed that antibiotics can treat common cold, and $32 \%$ think that they should stop the antibiotic once they start to feel improvement. In comparison, our study showed that more than half of the population would use antibiotics when they have common cold, and $42.2 \%$ thought that they would stop the antibiotic on symptoms remission, regardless of the course prescribed. As for the source of antibiotic, El Zowalaty et al. reported that $63.6 \%$ of participants purchased the antibiotics without prescription (8). In contrast, our study showed that only $27.6 \%$ of the participants took the antibiotic without physician prescription, and those who received non-prescribed antibiotics constituted $23.5 \%$ of compliant participants.

Our study shows that the participants have some misconceptions regarding the proper use of antibiotics. Further studies are required to assess the different aspects contributing to antibiotic resistance. Moreover, educational and awareness programs should be implemented to change the public beliefs about antibiotics.

Table 1:- Demographics - Compliance

\begin{tabular}{|c|c|c|c|}
\hline \multicolumn{2}{|c|}{ Value } & Compliant n (\%) & Non-Compliant n (\%) \\
\hline \multirow{2}{*}{ Age } & $=<30$ & $120(58.8)$ & $84(41.2)$ \\
& $>30$ & $123(74.1)$ & $43(25.9)$ \\
\hline \multirow{2}{*}{ Gender } & Male & $110(64.3)$ & $61(35.7)$ \\
& Female & $143(65.9)$ & $74(34.1)$ \\
\hline \multirow{2}{*}{ Nationality } & Saudi & $231(65.6)$ & $121(34.4)$ \\
\cline { 2 - 4 } & Non Saudi & $16(94.1)$ & $1(5.9)$ \\
\hline \multirow{2}{*}{ Marital Status } & Single & $77(61.1)$ & $49(38.9)$ \\
\cline { 2 - 4 } & Married & $158(69.3)$ & $70(30.7)$ \\
\multirow{2}{*}{ Education } & Undergraduate & $125(63.8)$ & $71(36.2)$ \\
& Postgraduate & $120(67.0)$ & $59(33)$ \\
\hline
\end{tabular}

Table 2:- Knowledge

\begin{tabular}{|c|c|c|}
\hline Questions & Yes n (\%) & No n (\%) \\
\hline $\begin{array}{l}\text { Do you think that the effectiveness of the antibiotic treatment } \\
\text { will decrease with the repetitive use? }\end{array}$ & $191(47.7)$ & $209(52.3)$ \\
\hline Would you use antibiotics when you have common cold? & $223(55.8)$ & $177(44.2)$ \\
\hline Do you read the pamphlet of the antibiotic medication? & $228(57.6)$ & $168(42.4)$ \\
\hline Do you check the expiry date of the antibiotic? & $262(65.3)$ & $139(34.7)$ \\
\hline $\begin{array}{l}\text { Do you keep the remaining of the drug after finishing the } \\
\text { course of treatment for next time? }\end{array}$ & $114(28.4)$ & $287(71.6)$ \\
\hline $\begin{array}{l}\text { Would you recommend an antibiotic medication based on your } \\
\text { experience? }\end{array}$ & $160(40.1)$ & $239(59.9)$ \\
\hline
\end{tabular}




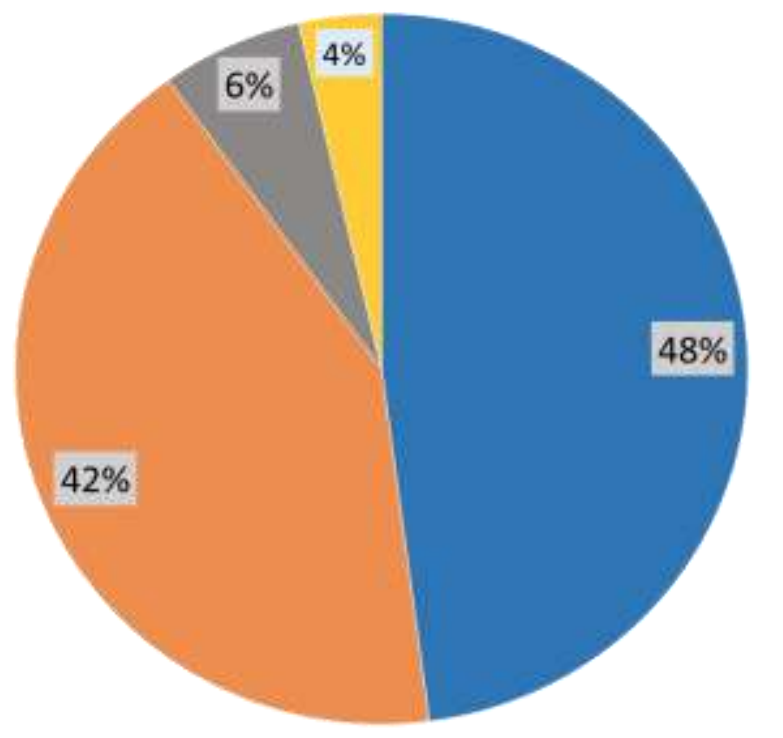

\section{Complete the course}

\section{Symptoms remission}

\section{Because of side effects}

No improvement

Graph 1:- When to stop antibiotics

Graph 2:- Source of Antibiotic Prescription - Compliance

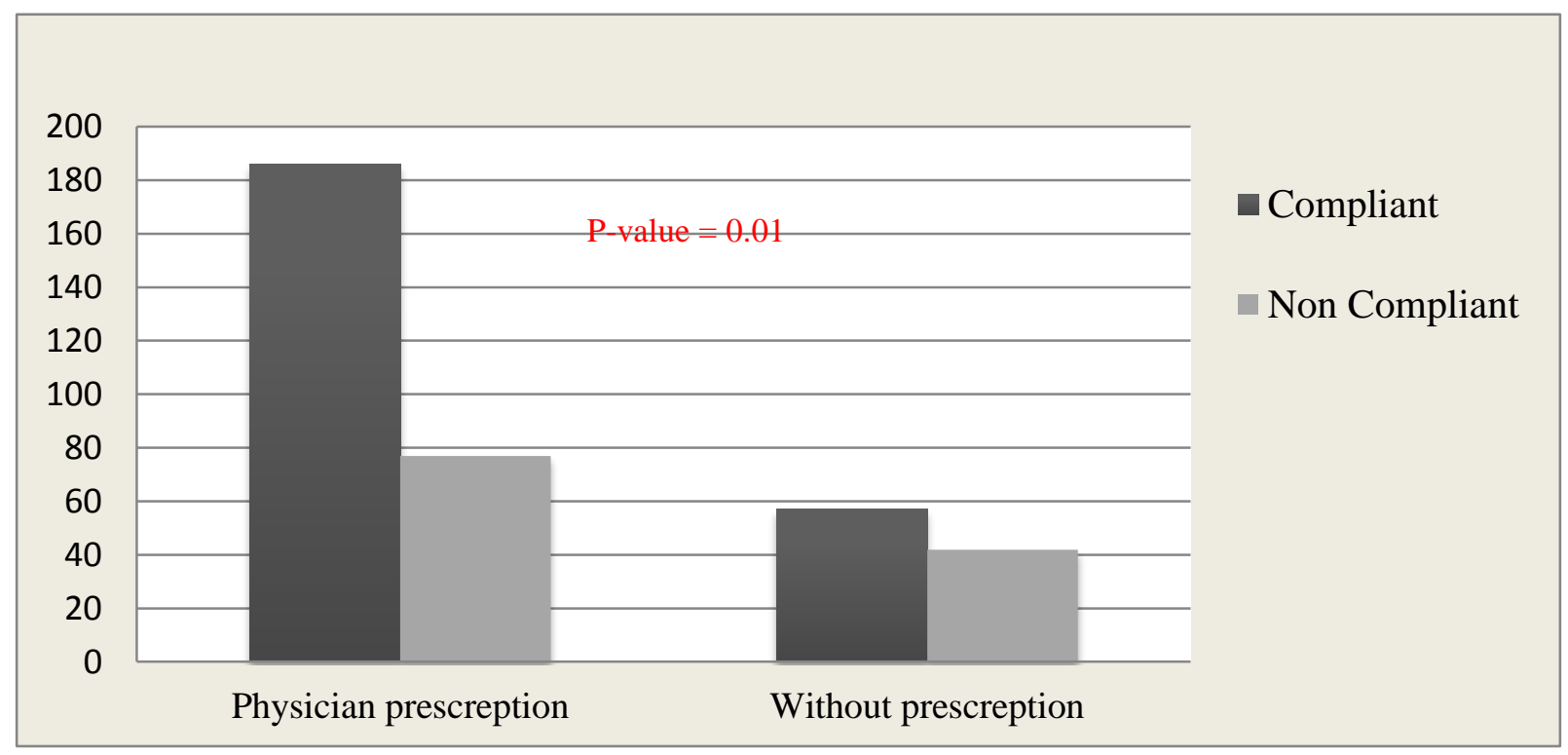

\section{Conclusion:-}

All these results suggest lack of knowledge on community level regarding antibiotic proper usage. Nevertheless, pharmacies in our country provide an easy access to antibiotics, and they even recommend their usage for patients who do not need them. The pharmacy aspect needs to be further evaluated to develop a better control over the dispensing system. Furthermore, patients need to receive a better explanation about the benefits and harms of antibiotics. In addition, they should be educated about the importance of following the prescribed course to decrease the microbial resistance. 


\section{Acknowledgment:-}

We would like to express our gratitude to Dr. Nadia Mazraani, Sahar Felfelan, Asmaa Othman, Yousif Abdullah, and Zekra Alsamadani for their efforts by helping in and facilitating the data collection process and to Khulood Bawazeer for the data entry.

\section{References:-}

1. Center for Disease Dynamics, Economics \& Policy. 2015. State of the World's Antibiotics, 2015. CDDEP: Washington, D.C .

2. CDC Global Health - Infographics - Antibiotic Resistance The Global Threat [Internet]. Cdc.gov. 2017 [cited 19 February 2017]. Available from: https://www.cdc.gov/globalhealth/infographics/antibiotic_resistance_global_threat

3. WHO multi-country survey reveals widespread public misunderstanding about antibiotic resistance [Internet]. World Health Organization. 2017 [cited 19 February 2017]. Available from: http://www.who.int/mediacentre/news/releases/2015/antibiotic-resistance/en/

4. Harada KAsai T. Role of Antimicrobial Selective Pressure and Secondary Factors on Antimicrobial Resistance Prevalence inEscherichiacolifrom Food-Producing Animals in Japan. Journal of Biomedicine and Biotechnology. 2010;2010:1-12.

5. Abdullah Alanazi et al. J Pharm Biomed Sci. 2013, April; 29 (29): 806-813.Available at jpbms.info

6. Al-Mohamadi A, Badr A, Mahfouz LB, Samargandi D, Al Ahdal A. Dispensing medications without prescription at Saudi community pharmacy: Extent and perception. Saudi pharmaceutical journal. 2013 Jan 31;21(1):13-8.

7. Abdulhak AA, Al Tannir MA, Almansor MA, Almohaya MS, Onazi AS, Marei MA, Aldossary OF, Obeidat SA, Obeidat MA, Riaz MS, Tleyjeh IM. Non prescribed sale of antibiotics in Riyadh, Saudi Arabia: a cross sectional study. BMC Public Health. 2011 Jul 7;11(1):538.

8. El Zowalaty ME, Belkina T, Bahashwan SA, El Zowalaty AE, Tebbens JD, Abdel-Salam HA, Khalil AI, Daghriry SI, Gahtani MA, Madkhaly FM, Nohi NI. Knowledge, awareness, and attitudes toward antibiotic use and antimicrobial resistance among Saudi population. International journal of clinical pharmacy. 2016 Oct $1 ; 38(5): 1261-8$. 